\title{
O Ensino de Empreendedorismo através de Jogos de Empresa: a modelagem do jogo "Cinema"
}

\author{
Francine Sacchis Gottfried, Giliane Bernardi \\ Centro Universitário Franciscano - UNIFRA, Santa Maria - RS \\ francinesacchis@gmail.com,giliane@unifra.br
}

Resumo. Este trabalho apresenta a proposta de modelagem e especificação de um jogo de empresa informatizado de apoio ao ensino de empreendedorismo. O mesmo é baseado em um jogo de empresa manual existente na literatura, denominado "Cinema" (Venture Capital), onde os alunos podem, através do mesmo, vivenciar experiências de negociação, tomada de decisão, iniciativa, liderança, criatividade e comunicação. $O$ processo de especificação do jogo está sendo realizado de acordo com a Engenharia de Software Orientada a Agentes, através do modelo organizacional MOISE+.

Palavras-Chave: Jogos de empresa, Engenharia de Software Orientada a Agentes, MOISE+, Empreendedorismo

"The Entrepreneurship Teaching through by an Enterprise Game: the "Cinema" game modeling”

Abstract. This paper presents a modeling and specification proposal of a computer enterprise game to support the teaching of entrepreneurship discipline. The model is based in a classic game of literature, as know as "Cinema" (Capital Venture). The students can improve yours negotiations skills, decision making, initiative, leadership, creativity and communication. The specification process is being done through the Agent-Oriented Software Engineering (AOSE), using the organizational model MOISE+.

Keywords: Enterprise game, Agent-oriented Software Engineering, MOISE+, Entrepreneurship 


\section{Introdução}

Diversos cursos de graduação possuem em sua matriz curricular a disciplina de Empreendedorismo. Nos cursos da área de Computação esta disciplina tem como objetivo principal despertar nos alunos o espírito empreendedor, como uma alternativa e habilidade a ser explorada no seu futuro profissional. Os cursos caracterizam-se por formarem profissionais que poderão atuar na área de análise e desenvolvimento de sistemas, seja como funcionários em empresas de terceiros, seja como gestores de seus próprios empreendimentos. Para David et al. (2001), não basta que apenas o empresário ou proprietário possua um caráter empreendedor, sendo que o autor considera que as pessoas que trabalham nas organizações devem ser e agir como empreendedores também.

Na disciplina de Empreendedorismo, usualmente, são trabalhados aspectos relacionados à caracterização de um empreendedor, a nova realidade do mercado e das empresas, bem como planos de negócios para a criação e gestão de empreendimentos de sucesso. Entre os mecanismos utilizados como suporte a prática pedagógica no ensino de empreendedorismo podem ser citados os estudos de caso, as aulas expositivas, dinâmicas de grupo e a utilização de jogos de empresa, sendo estes, normalmente, representados através de execuções manuais (em sala de aula, conhecidos como pen and paper, ou através de jogos de tabuleiro).

Nos jogos de empresa, os alunos são inseridos no papel de jogadores que, através da formação de equipes, realizam atividades de criação e gestão de empreendimentos das mais diversas áreas de negócios. O professor, na maioria dos casos, assume o papel de moderador e analista das decisões que estão sendo tomadas, de forma a conduzir o processo e futuramente discutir as ações tomadas pelos alunos. Jogos de Empresa informatizados podem se tornar uma prática pedagógica motivadora e atrativa para que os alunos participem mais ativamente deste tipo de atividade.

Além disso, observa-se que a modelagem do jogo, utilizando uma abordagem baseada em agentes de software, pode tornar a representação dos papéis atribuídos aos participantes, bem como a modelagem de suas responsabilidades, mais esclarecedora e consistente.

O objetivo principal deste artigo é apresentar a modelagem de um jogo de empresa para a prática de questões relacionadas a empreendedorismo, sendo que a mesma está sendo desenvolvida através da metodologia de modelagem orientada a agentes MOISE+.

\section{Engenharia de Software Orientada a Agentes}

A Engenharia de Software pode ser vista como um conjunto de métodos, ferramentas e procedimentos (processos) que auxiliam em todas as etapas do desenvolvimento de um sistema computacional (Pressman. 2006). Ela se preocupa com o produto final, bem como com o processo que permeia o mesmo, buscando sempre ao longo de todo o desenvolvimento manter o foco na qualidade do mesmo.

No entanto, a Engenharia de Software tradicional é considerada uma abordagem adequada para o desenvolvimento de software com comportamento predefinido, onde os processos de negócios a serem informatizados são conhecidos e não sofrem mudanças consideráveis ao longo do tempo. Existem processos de negócios que exigem adaptações constantes, devido a sua complexidade e por operarem em ambientes em 
constante modificação. Assim, surge a necessidade de adaptação dos processos tradicionais, de forma a contemplar tais necessidades.

Neste contexto, o uso de agentes pode ser visualizado como uma abordagem consistente para realizar a especificação de sistemas com tais características. Assim a Engenharia de Software Orientada a Agentes (AOSE - Agent-Oriented Software Engineering) está sendo considerada um novo paradigma a ser explorado dentro da área de Engenharia de Software para auxiliar no desenvolvimento de sistemas que utilizem a concepção de agentes para operacionalizar suas tarefas.

Para Jennings (2000), o principal objetivo da Engenharia de Software Orientada a Objetos consiste em criar metodologias e ferramentas que possibilitem o desenvolvimento e manutenção de sistemas baseados em agentes, sendo que estes sistemas devem ser flexíveis, fáceis de usar, adaptáveis e de alta qualidade.

Um conjunto de benefícios pode ser obtido no desenvolvimento de sistemas dentro da perspectiva de orientação a agentes, sendo que Collier (2002) destaca alguns na área de Engenharia de Software:

- Disponibilidade de diversos instrumentos de impacto para tomada de decisão: agentes são capazes de tomar a iniciativa independentemente de qualquer controle global do sistema. Esta autonomia, que é suportada por sistemas de raciocínio usualmente expressivos, permite que os mesmos possam tomar decisões importantes nos processos de negócio;

- Abordagens baseadas em agentes simplificam sistemas distribuídos complexos através da abstração: isto ocorre através do gerenciamento da complexidade, conseqüentemente, facilitando a escalabilidade de sistemas;

- Suporte para padrões flexíveis de interação: abordagens baseadas em agentes implementam mecanismos de interação de agentes em alto nível, através de Linguagens de Comunicação entre Agentes (ACL - Agent Communication Language), baseadas em modernas teorias da fala que permitem o emprego de um grande número de estratégias de negociação, fundamentais para processos empresariais;

- Abordagens baseadas em agentes suportam a criação de aplicações abertas: sistemas multiagentes permitem que, à medida que um determinado problema não pode ser resolvido pelos agentes existentes, sejam adicionados novos agentes com habilidades e funcionalidades apropriadas; e

- Robustez das Aplicações: sistemas multiagentes proporcionam um aumento da robustez dos sistemas através da redundância, autonomia e flexibilidade. Por exemplo, em um determinado cenário, se um determinado agente precisa do auxílio de um agente para executar uma tarefa e este não está disponível, ele deve automaticamente localizar outro agente para realizar a mesma tarefa.

O desenvolvimento do processo de AOSE é similar ao processo de Engenharia de Software tradicional, onde o sistema é representado em vários níveis de abstração e detalhamento. Diversas metodologias têm sido propostas para a etapa de modelagem de sistemas orientados a agentes Dentre estas metodologias, encontra-se o Modelo Organizacional MOISE+, que prevê a modelagem de sistemas orientados a agentes, centrando a modelagem na organização em que os agentes estão inseridos e atuando. A próxima seção apresenta este modelo, por ter sido o escolhido para modelar o jogo proposto. 


\section{Jogos de Empresa}

Os Jogos de Empresa podem ser definidos como simulações empresariais, onde os participantes avaliam e analisam cenários para um maior aprimoramento e aperfeiçoamento das decisões a serem tomadas. Além de incentivarem os participantes, os jogos de empresa trazem consigo uma adequada aprendizagem sobre 0 comportamento do grupo e um importante reforço de toda a teoria da tomada de decisão.

O uso de Jogos de Empresa oferece o desenvolvimento de determinadas habilidades, tais como: capacidade de organização, percepção de modelos comportamentais e atitudinais, desenvolvimento de estratégias de planejamento, exercício de tomada de decisão, competência em priorizar e agir pró-ativamente, aprimoramento das relações sociais, na comunicação intra e intergrupais, entre outras.

Segundo Gramigna (1993), antes de tomar a decisão de estruturar um jogo é necessário familiarizar-se com ele. Para tanto, é interessante realizar uma análise das seguintes etapas: análise dos objetivos; auxílio técnico; nível de complexidade da tarefa a ser proposta; análise da clientela, ou seja, do perfil dos participantes; espaço disponível para a atividade; sistemas de papéis; definição da mecânica lúdica; realização de um laboratório teste; e preparação de todas as atividades do ciclo vivencial. Para a preparação das atividades do ciclo vivencial é necessário considerar alguns aspectos, tais como:

- Vivência: corresponde a fase inicial, onde o facilitador poderá oferecer diversas atividades;

- Relato: momento no qual o facilitador oferece espaços ao grupo para compartilhar sentimentos, reações e emoções;

- Processamento: é o momento em que os participantes têm a oportunidade de analisar o ocorrido durante o jogo, avaliando sua atuação e estabelecendo relações com o resultado obtido;

- Generalização: ocorre quando o grupo faz comparações e analogias do jogo ao seu cotidiano empresarial; e

- Aplicação: ao final, é necessário preparar atividades que dêem margem à aplicação do que foi vivenciado e discutido. Assim, todas as conclusões e análises realizadas pelo grupo servirão de subsídio para o estabelecimento de melhorias e mudanças.

Uma vantagem da utilização de jogos de empresa é mostrar aos participantes as conseqüências progressivas de suas decisões. Em outras palavras, os jogos incluem a variável 'tempo' como um aspecto principal, permitindo que, através da simulação, possa se cumprir num certo espaço de tempo, vários anos de experiência. Segundo Cornélio Filho (1998), utilizar recursos computacionais para simular situações empresariais que contemplem os aspectos descritos, promove um desenvolvimento mais rápido e qualificado da empresa, devido às experiências adquiridas nas tomadas de decisões impostas pelos jogos, relacionadas com diversas situações que são simuladas aos participantes.

Pode-se afirmar que a simulação é uma alternativa que oferece a possibilidade de criar cenários, semelhantes aos reais, porém de maneira simplificada, copiando do evento original os seus princípios fundamentais. Desta forma, pretende-se aplicar o conceito de jogos de empresa, realizando a modelagem de um jogo voltado para o 
ensino de empreendedorismo, buscando a aprendizagem e aprimoramento de habilidades consideradas cruciais para um empreendedor na gestão de seus negócios.

\section{O Modelo MOISE+}

Para Hubner e Sichmann (2007), dos quatro aspectos que formam um Sistema Multiagentes (os agentes, a interação entre eles, o ambiente e sua organização), a organização, normalmente, está definida implicitamente no sistema. Através da organização, os agentes inseridos em um ambiente podem atuar, obtendo informações que os auxiliem a tomar decisões, tornando-se assim um aspecto fundamental na execução de um sistema orientado a agentes.

O modelo MOISE+ (Hubner, 2003) é uma extensão do MOISE e se apresenta como um modelo de organização que considera a especificação organizacional do ambiente, definindo papéis, funcionalidades e responsabilidades aos agentes envolvidos. O modelo MOISE+ possui noções centrais de especificação organizacional que um grupo de agentes adota, formando uma entidade organizacional para atingir uma finalidade.

A construção do modelo MOISE+ é baseada em três aspectos principais: o estrutural, que define os papéis e como estes se relacionam na organização; o funcional, que se refere aos objetivos globais que devem ser alcançados e que são expressos através de metas, missões e planos de organização; e o deôntico, que liga o modelo estrutural e o funcional definindo as responsabilidades dos papéis no plano global (Silva, 2006). Uma visão geral do modelo MOISE+ pode ser visualizada na figura 1.

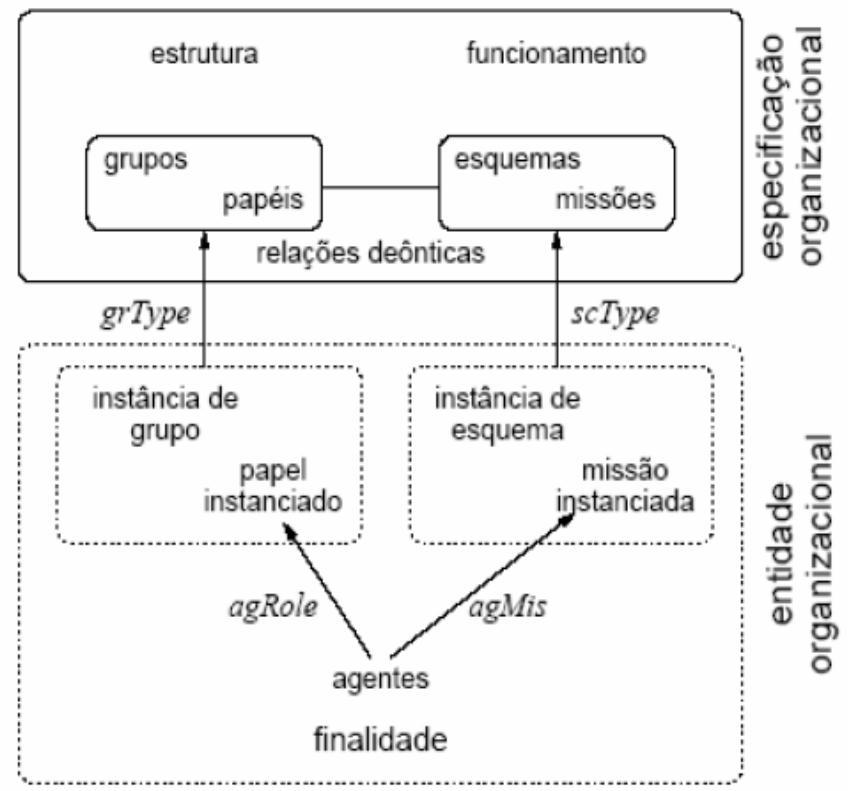

Figura 1. Visão geral do modelo MOISE+ (Fonte: Hubner, 2003)

Assim, o modelo MOISE+ é uma concepção centrada na organização, permitindo a especificação dos aspectos organizacionais de forma independente e tornando explícita a finalidade do sistema, o que pode se tornar uma solução adequada para a representação dos agentes e seus papéis e das responsabilidades e organização do jogo proposto. 


\section{Estudo de Caso: O Jogo de Empresa “Cinema” (Venture Capital)}

O jogo proposto é baseado em um jogo de empresa apresentado em Vicente (2001), denominado "Cinema" (Venture Capital), que tem como principal objetivo colocar os alunos na posição de CEO (tomador de decisão) de uma empresa cinematográfica, gerenciando os recursos, sendo que cada aluno atuará como um agente humano, representando o papel de "Jogador".

Os alunos poderão formar equipes e, atuando dentro de equipes, terão um determinado comportamento a seguir, bem como um conjunto de procedimentos a executar. As equipes poderão ser formadas apenas por agentes humanos (por exemplo, colegas de sala), ou um aluno poderá montar uma equipe escolhendo agentes de software.

Usualmente, um dos jogadores representará o papel de "Líder” da equipe, sendo que poderá deliberar sobre as atividades a serem desempenhadas por cada participante (estratégia da organização). Com relação às equipes, as mesmas poderão ser formadas apenas por grupos contendo jogadores humanos (jogo entre colegas de sala) ou um grupo poderá ser formado com elementos apenas de agentes de software (jogo contra o computador). O líder vai ter autoridade sobre os jogadores e os jogadores só poderão se comunicar com jogadores da mesma equipe (relacionamento intra-grupo). Quanto à cardinalidade, uma equipe será bem formada se um e somente um agente assumir o papel de líder e se um ou vários agentes assumirem o papel de jogador.

Cada Equipe inicia o jogo com um determinado valor em caixa, que deve ser utilizado para a produção de filmes e gerenciamento dos mesmos. O jogo é dividido em turnos, onde cada turno representa um ano fiscal e nestes acontecerão várias fases em uma determinada seqüência.

Na Fase de Planejamento, a equipe decide quais filmes irão rodar em cada categoria, sendo que cada equipe poderá rodar, no máximo, um filme em cada categoria. A qualidade dos filmes é avaliada conforme o número de estrelas, sendo que o filme que tiver uma estrela é de baixíssima qualidade (custo mais baixo para sua produção) e o filme de cinco estrelas é uma super produção (tendo custo mais elevado para sua produção). Cabe salientar que a equipe é quem decide a categoria do filme e as regras e conseqüências são delimitadas dependendo desta escolha.

Na fase de Revelação, as equipes informam suas decisões ao agente que tem o papel de Moderador no processo de revelação e discussão dos dados às demais equipes. No jogo de empresa tradicional, o papel de Moderador é atribuído ao professor da disciplina. Nesta proposta, pretende-se possibilitar que o professor possa atuar como um agente humano representando este papel, bem como permitir que um agente de software possa ser o Moderador, fazendo com que o aluno possa jogar, mesmo que distante da sala de aula. Assim, características e tarefas serão atribuídas a este agente, de forma que possa interagir com os jogadores eficientemente. Eventualmente, o professor pode desejar passar a responsabilidade de Moderador para um aluno da turma, passando esta responsabilidade para ele. Ainda, têm-se as fases de Cálculo e a fase de Fim do Ano Fiscal, onde os rendimentos líquidos do ano são computados e avaliados.

Ao final do jogo, o professor novamente age, seja de forma humana, ou como um agente de software, no papel de Analista, onde serão questionadas e analisadas as ações e tomadas de decisão executadas no decorrer do mesmo. Assim como no caso do Moderador, o professor pode passar a responsabilidade de Analista para um aluno 
possibilitando aos alunos assumirem uma posição de críticos e revisores do processo, sendo que este Analista pode se comunicar com o Moderador independente de equipe (relacionamento inter-grupo).

Quanto à cardinalidade de um jogo, este será bem formado se um e somente um agente assume o papel de Analista e se um e somente um agente assume o papel de Moderador. Para que o jogo inicie é necessário no mínimo uma ou várias equipes. A figura 2 apresenta a especificação estrutural do jogo proposto, utilizando o modelo MOISE+.

Observa-se a criação de um papel Membro Externo, além de Aluno e Professor, tornando possível que o professor de uma disciplina traga membros externos (por exemplo, profissionais da área, ou seja, do meio empresarial) para atuarem na posição de Moderador e Analista do processo, permitindo que o mesmo seja enriquecido com contribuições diversas.
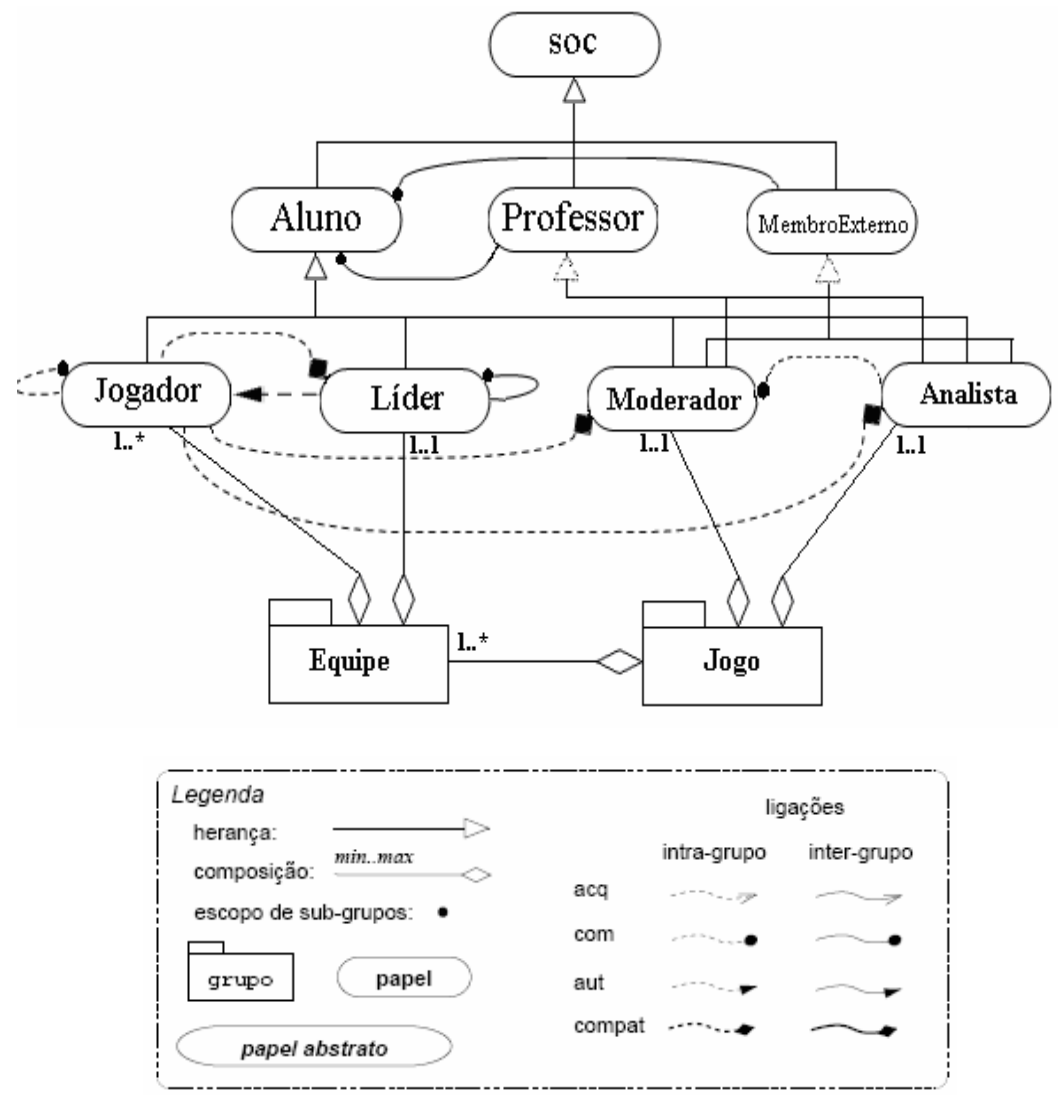

Figura 2. Especificação Estrutural do Jogo Proposto com o Modelo Moise+

Observa-se a criação de um papel Membro Externo, além de Aluno e Professor, tornando possível que o professor de uma disciplina traga membros externos (por exemplo, profissionais da área, ou seja, do meio empresarial) para atuarem na posição de Moderador e Analista do processo, permitindo que o mesmo seja enriquecido com contribuições diversas.

Uma especificação estrutural apresenta três níveis representativos: o individual, com a definição dos papéis; o social, com a definição das relações entre eles; e a coletiva, com o agrupamento de papéis. Neste estágio a especificação estrutural 
encontra-se definida conforme o modelo de organização proposto. Futuramente serão desenvolvidas as funções que cada papel assume e a relação entre papéis e funções.

\section{Considerações Finais}

Espera-se, com o desenvolvimento deste jogo, que os alunos possam, de forma simulada, interagir em processos que os preparem para situações que poderão surgir em suas vidas profissionais, associando ao prazer lúdico a capacidade de raciocínio e tomada de decisão.

O jogo está sendo modelado de forma que possa ser executado tomando como referência o ciclo vivencial descrito por Gramigna (1993), permitindo que os alunos, juntamente com o professor, possam analisar e refletir sobre as decisões tomadas, de forma a melhorar suas habilidades, tornando sua aprendizagem mais significativa e permitindo que, futuramente, diferentes estratégias possam ser aplicadas quando da execução do jogo novamente.

No modelo MOISE+, o conceito de papel tem função primordial por ser um elo de ligação entre o agente e a organização. Assim, esta ligação tem tanto uma dimensão estrutural, que é estabelecida quando um agente assume um papel, quanto funcional, que é estabelecida quando um agente se compromete com uma missão. Estas características estão presentes na modelagem do jogo proposto, definindo regras e restrições de comportamento dos agentes em seus papéis, bem como ao executar tarefas a eles determinadas.

O sistema proposto encontra-se, atualmente, em fase de modelagem, onde os agentes e seus papéis estão sendo definidos e especificados, bem como o ambiente em que os mesmos estarão atuando e as relações e atividades destes junto ao ambiente. Pretende-se, ao final da etapa de modelagem e especificação, realizar uma validação dos modelos gerados junto a professores da disciplina de Empreendedorismo, de forma a verificar se o mesmo está executando de forma correta todas as especificações do jogo proposto por Vicente (2001) e, principalmente, se atende às necessidades pedagógicas para ser utilizado em sala de aula. Após esta etapa de validação, o mesmo será implementado e implantado para testes e validações de execução.

\section{Referências Bibliográficas}

Collier, R.W. Agent Factory: A Framework for the Engineering of Agent-Oriented Applications, Tese (Doutorado), Universidade Nacional da Irlanda. 2002

Cornélio Filho, P. O Modelo de Simulação do GPCP-1: Jogo do Planejamento e Controle da Produção, Dissertação (Mestrado), Pós-Graduação em Engenharia da Produção e Sistemas, UFSC, Florianópolis. 1998.

David, D. E. H., Roveda, M. V., Redivo, R. B., Gauthier, F. A. O., Colossi, N., Franzoni, A. M. B. Aspectos Pedagógicos no Ensino do Empreendedorismo, III Encontro Nacional de Empreendedorismo, ENE-UFSC. 2001.

Girardi, R. Engenharia de Software Baseada em Agentes, IV Congresso Brasileiro de Ciência da Computação - CBCOMP. Itajaí, SC. ed. 39. 2004.

Gramigna, M.R.M. Jogos de Empresas. São Paulo: Makron Books. 1993.

Hubner, J.F., Sichman, J.S. Organização e Sistemas Multiagentes, Workshop-Escola de Sistemas de Agentes para Ambientes Colaborativos - WESAAC. Universidade Católica de Pelotas, RS, Brasil. 16 a 18 de abril. 2007. 
Hubner, J.F. Um Modelo de Reorganização de Sistemas Multiagentes. Tese (Doutorado) - Departamento de Engenharia de Computação e Sistemas Digitais. São Paulo. 2003.

Jennings, N. R. On Agent-Based Software Engineering, Artificial Intelligence, v. 117, pp277-296. 2000.

Konzen, A. A. Especificação de Requisitos de Agentes de Usuário em Z, Dissertação (Mestrado), Pós-Graduação em Ciência da Computação, PUC/RS. 2002.

Vicente, P. Jogos de Empresa, São Paulo: Makron Books. 2001 